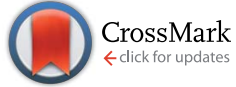

Cite this: RSC Adv., 2017, 7, 13390

Received 2nd November 2016 Accepted 13th January 2017

DOI: $10.1039 / c 6 r a 26186 h$

rsc.li/rsc-advances

\section{Phosphazene-based novel organo-inorganic hybrid salt: synthesis, characterization and performance evaluation as multifunctional additive in polyol}

\author{
Raj K. Singh, ${ }^{*}$ Aruna Kukrety, Rakesh C. Saxena, Ajay Chouhan, Suman L. Jain \\ and Siddharth S. Ray
}

A novel organo-inorganic hybrid salt, namely, hexa-P- $\left(N, N^{\prime}\right.$-dimethylaminomethyl-3,5-di-tert-butyl-4hydroxyphenyl)cyclotriphosphazene hexachloride $\left[\mathrm{N}_{3} \mathrm{P}_{3}\left\{-\mathrm{N}\left(\mathrm{R}^{1}\right)_{2}-\mathrm{CH}_{2}-\mathrm{C}_{6} \mathrm{H}_{2}(\mathrm{OH}) \mathrm{R}_{2}^{2}\right\}_{6}\right] 6 \mathrm{Cl}^{-}\left(\mathrm{R}^{1}=\mathrm{CH}_{3}, \mathrm{R}^{2}=\right.$ $\left.\mathrm{C}\left(\mathrm{CH}_{3}\right)_{3}\right)$, which was denoted as $P z P(-N H P)_{6}$, was synthesized by the reaction between hexachlorocyclotriphosphazene $\left(\mathrm{N}_{3} \mathrm{P}_{3} \mathrm{Cl}_{6}\right)$ and 2,6-di-tert-butyl-4-(dimethylaminomethyl)phenol in dichloromethane. The synthesized salt was characterized using elemental analysis (CHN), UV-vis, infrared (IR), and nuclear magnetic resonance (NMR) spectroscopy, and thermogravimetry (TG). The salt was then evaluated as a multifunctional antioxidant, anticorrosion, antiwear and antifriction additive in a polyol lube base oil. $P z P(-$ $N H P)_{6}$ was found to display excellent antioxidant and moderate anticorrosion properties as estimated by the RBOT (rotating bomb oxidation test) according to ASTM D2272 and standard corrosion test procedures, respectively. Four-ball tests according to ASTM D4172B were performed in order to evaluate its antiwear and antifriction characteristics in terms of the average wear scar diameter (AWSD) and average friction coefficient, respectively. It was found that $P z P(-N H P)_{6}$ at a doping concentration of $3000 \mathrm{ppm}$ reduced the AWSD of the blank polyol from $695.83 \pm 16.86$ to $585.83 \pm 11.72 \mu \mathrm{m}$, whereas the average friction coefficient decreased from $0.110 \pm 0.0077$ to $0.080 \pm 0.0097$.

\section{Introduction}

The disposal of lubricants after use and oil drained from lubricating systems causes severe environmental problems to land and water. The quality of air is also adversely affected owing to volatile organic compounds (VOC) generated by the degradation of lubricants during their operational life or after their disposal. Owing to the widespread use of lubricants, human health is in a compromising situation as a result of industrial development. ${ }^{1,2}$ Because the use of lubricants is indispensable in the current situation, the key problem is their toxic and non-biodegradable nature, which has attracted the attention of modern researchers to develop new environmentally benign lubricant technologies. ${ }^{3}$ To formulate an ecofriendly lubricant, both the lube base oil and the additives should be nontoxic. As far as base oils are concerned, vegetable oil-based esters have emerged strongly as an alternative choice for ecofriendly lube base oils, with performance on par with that of mineral base oils. ${ }^{4}$ In the case of additives, no alternative ecofriendly additive technology has emerged in the past few years. This is the reason why the use of additives such as zinc dialkyldithiophosphate (ZnDDP) has continued since its

Chemical Science Division, CSIR-Indian Institute of Petroleum, P.O. Mohkampur, Dehradun - 248 005, Uttarakhand, India. E-mail: rksingh@iip.res.in; Fax: +91-1352660202; Tel: +91-135-2525708 discovery in the 1940s despite containing harmful components such as $\mathrm{P}, \mathrm{S}$ and heavy metals, which cause serious environmental and health problems. ${ }^{5}$ Certainly, other reasons are also responsible for its wide use, e.g. its high performance characteristics and multifunctionality. ${ }^{6}$ Although additives are used in low quantities, the use of such conventional toxic additives may impair the biodegradability characteristics of the entire lube formulation. Therefore, the entire paradigm of research into additives is now shifting towards the development of novel multifunctional additives with low toxicity.

Phosphazene is a cyclic molecule containing alternating nitrogen and phosphorus atoms. Recently, attention has been paid to the development of additives derived from phosphazene that have polar functionalities capable of interacting with tribological surfaces and a smaller number of toxic elements in comparison to ZnDDP. Some efforts have been made to use the phosphazene framework in tribological applications but in different media and on distinct tribological surfaces, in the recent past. For example, ionic liquids based on polyquaternary phosphazene salts were synthesized and evaluated as boundary lubricant additives for their friction and wear properties at a concentration of $0.25 \mathrm{wt} \%$ in water on silicon nitride ceramic interfaces. ${ }^{7}$ Hexakis(1,1,5-trihydroperfluoropentoxy)cyclotriphosphazene and bridged alkoxycyclotriphosphazene were evaluated as additives in a perfluoropolyether-type lubricant. Their friction and wear behaviour on a steel-on-steel system was investigated 
using an SRV oscillating friction and wear tester, and it was found that both were effective in improving the tribological performance of the lubricant. ${ }^{8}$ Cyclic phosphazenes were employed as additives to passivate and stabilize perfluoropolyether lubricants from the perspective of decomposition and to enhance their durability for applications at the head/disk interface. ${ }^{9}$ Two novel synthetic linear phosphazene oligomers were investigated as lubricants for steel-on-steel contact using an oscillating friction and wear tester. Both were found to be comparatively more effective than perfluoropolyether (PFPE) lubricants in their friction and wear behaviour. ${ }^{10}$ A novel lubricant based on cyclotriphosphazene substituted with perfluoropolyether (PFPE) chains and a glycerol unit derived from phenol was prepared. This new lubricant, owing to the presence of PFPE, cyclotriphosphazene and polar hydroxyl groups, provided balanced physical and tribological properties in comparison to perfluoropolyether lubricants. ${ }^{\mathbf{1 1}}$

Our proficiency and experience, which are reflected in current reports of the design and development of multifunctional lubricant additives by incorporating hindered phenolic moieties into polar organic entities that displayed surface interaction properties and lower toxicity, prompted us to investigate the utility of a phosphazene molecule in the present study. ${ }^{12-15}$ A previous report is also available where a phosphazene compound substituted with amine and hindered phenol (mono-(3,5-di-tert-butyl-4-hydroxyphenoxy)-pentakis(dimethylamino)cyclotriphosphazene) was employed as an antioxidant additive for aqueous-based compositions. ${ }^{16}$ In view of this, we herein designed and synthesized a novel organo-inorganic hybrid salt based on a substituted phosphazene molecule with six hindered phenolic moieties, namely, $N, N^{\prime}$-dimethylaminomethyl3,5-di-tert-butyl-4-hydroxyphenyl groups. After the characterization of this synthesized salt using elemental analysis (CHN), UVvis, infrared (IR), and nuclear magnetic resonance (NMR) spectroscopy, and thermogravimetric (TG) techniques, it was evaluated as a multifunctional antioxidant, anticorrosion, antiwear and antifriction additive in a polyol lube base oil.

\section{Experimental}

\section{Materials}

Hexachlorocyclotriphosphazene and 2,6-di-tert-butyl-4-(dimethylaminomethyl)phenol were purchased from Sigma-Aldrich. Dichloromethane, diethyl ether, xylene and isopropanol were purchased from Mark Millipore, Germany and used as received. Pentaerythritol tetraoleate (polyol) was purchased from Mohini Organics Pvt. Ltd, Mumbai, India.

\section{Synthesis of $P z P(-N H P)_{6}$}

First, $1.7 \mathrm{~g}$ ( $5 \mathrm{mmol})$ hexachlorocyclotriphosphazene and $10 \mathrm{~mL}$ dichloromethane were charged into a dry $50 \mathrm{~mL}$ round-bottom flask kept in an oil bath fitted on a hot plate and equipped with a condenser and magnetic stirring bar. Then, $7.9 \mathrm{~g}$ (30 mmol) 2,6-di-tert-butyl-4-(dimethylaminomethyl)phenol dissolved in $20 \mathrm{~mL}$ dichloromethane was added slowly over a period of one hour under a nitrogen atmosphere without heating. The flask was completely sealed with Teflon tape and was heated at $50{ }^{\circ} \mathrm{C}$ for an additional 5-6 h. The heating device was turned off and the reaction medium was allowed to cool to ambient temperature under stirring. After completion of the reaction, the solvent was removed under reduced pressure using a rotary evaporator to obtain an orange-colored waxy organo-inorganic hybrid salt. Washing was performed with diethyl ether three times to obtain the pure compound. The obtained percentage yield of the final product $\boldsymbol{P} z \boldsymbol{P}(-\mathbf{N H P})_{6}$ was $97 \%$.

\section{Characterization}

The synthesized organo-inorganic hybrid salt $\boldsymbol{P z P}(-\mathbf{N H P})_{6}$ was characterized using various analytical techniques. CHNS analysis was performed with a PerkinElmer Series II CHNS/O 2400 analyzer. Optical spectra in the UV-vis region were recorded with a Shimadzu UV-2600 UV-vis spectrophotometer using cuvettes with a path length of $1 \mathrm{~cm}$ at room temperature. Fourier transform infrared (FTIR) spectra were recorded using a Thermo Nicolet 8700 research spectrophotometer by the $\mathrm{KBr}$ pellet method with a resolution of $4 \mathrm{~cm}^{-1}$. NMR spectra were also recorded with a Bruker Avance 500 spectrometer in proton noise-decoupling mode with a standard $5 \mathrm{~mm}$ probe. A PerkinElmer EXSTAR TG/DTA 6300 analyzer was used for recording thermogravimetry curves using aluminum pans. The experiments were carried out under a continuous nitrogen flow of 200 $\mathrm{mL} \min ^{-1}$. The temperature ramp rate was set at $10{ }^{\circ} \mathrm{C} \mathrm{min}^{-1}$. The mass loss was recorded from 30 to $800{ }^{\circ} \mathrm{C}$.

\section{Antioxidant test}

The performance of $\boldsymbol{P z} \boldsymbol{P}(-\mathbf{N H P})_{6}$ as an antioxidant additive was evaluated by analyzing salt-doped polyol samples using an RBOT (rotating bomb oxidation test) apparatus manufactured by Stanhope-Seta (UK) according to ASTM method D2272 (ref. 17) at $150{ }^{\circ} \mathrm{C}$. In this specific test, blended samples were weighed out at $50.0 \pm 0.5 \mathrm{~g}$ and placed in an oxidation vessel, to which $5.0 \mathrm{~mL}$ reagent water was added together with a copper wire catalyst cleaned with 220 grit silicon carbide sandpaper and molded into the form of a spring coil with an outside diameter of 44-48 $\mathrm{mm}$, a weight of $55.6 \pm 0.3 \mathrm{~g}$ and a height of 40-42 $\mathrm{mm}$. Then, the bomb was assembled and slowly purged twice with $90.0 \pm 0.5 \mathrm{psi}(620 \mathrm{kPa})$ oxygen. The bomb was then immersed in water to check for leaks, and the outer surface of the wet vessel was cleaned by any convenient means such as an air blast or towel. After this, the vessel was inserted into an oil bath carriage at $150{ }^{\circ} \mathrm{C}$. The test was considered to be complete after the pressure fell by more than $175 \mathrm{kPa}$ from the original pressure, and the RBOT time was noted down. All samples were run in duplicate, and the average RBOT time was reported.

\section{Anticorrosion test}

The anticorrosion property of the $\boldsymbol{P z} \boldsymbol{P}(-\mathbf{N H P})_{6}$ additive was evaluated using a standard corrosion testing procedure. ${ }^{18,19}$ First, by machining and milling, carbon steel metal was cut into small pieces with dimensions of $15 \mathrm{~mm} \times 10 \mathrm{~mm} \times 2 \mathrm{~mm}$ (area $0.6 \mathrm{in}^{2}$ ). These metal pieces were hand-polished using carborundum emery paper of grade number C $201 \mathrm{AH}$ extra fine and degreased using a xylene-isopropanol mixture $(1: 1)$. The 
degreased coupons were weighed to an accuracy of $0.1 \mathrm{mg}$ and suspended using a Teflon thread separately in base oil and doped base oils kept in stoppered measuring cylinders. The samples were kept undisturbed in an air oven for the next 25 days $(600 \mathrm{~h})$ at $110{ }^{\circ} \mathrm{C}$. After 25 days, estimates of the level of corrosion of the immersed metal specimens were made qualitatively and quantitatively by derusting the specimens using a derusting solution ( $36 \% \mathrm{HCl}$ containing $\left.5 \% \mathrm{Sb}_{2} \mathrm{O}+4 \% \mathrm{SnCl}_{2}\right)$. Finally, the metal specimens were weighed to an accuracy of \pm $0.1 \mathrm{mg}$, the weight loss of each metal test sample was recorded, and the corrosion rate was calculated according to eqn (1):

$$
\begin{aligned}
\text { Corrosion rate } & =\frac{\mathrm{wt} \text { loss } \times 15.5}{(\text { area })(\text { time })} \\
& =\text { mg per sq. dm per day or mdd }
\end{aligned}
$$

By taking the density of carbon steel $\left(7.8 \mathrm{~g} \mathrm{~cm}^{-3}\right)$ into account, the penetration rate was also calculated according to eqn (2):

$$
\begin{aligned}
\text { Penetration rate } & =\frac{\mathrm{wt} \text { loss } \times 22.3}{(\text { area })(\text { time })(\text { metal density })} \\
& =\text { mils per year or mpy }
\end{aligned}
$$

where weight loss is expressed in $\mathrm{mg}$; area in sq. inches of metal surface exposed; time in days exposed; density in $\mathrm{g} \mathrm{cm}^{-3}$.

Moreover, a qualitative estimate of the level of corrosion was also made by determining the total acid number (TAN) of the samples before and after the corrosion test according to the ASTM standard test method D664-11a. ${ }^{20}$

\section{Lubricity test}

Standard tribological tests according to ASTM D4172B ${ }^{21}$ were conducted using a four-ball wear testing machine from Ducom (India) on base fluid samples doped with the $\boldsymbol{P z P}(-\mathbf{N H P})_{6}$ additive to determine its antiwear and antifriction properties in terms of the average wear scar diameter (AWSD) and average friction coefficient. The typical four-ball setup consists of a rotating $12.7 \mathrm{~mm}$ steel ball having a load of $392 \mathrm{~N}$ in contact with three similar stationary balls kept in a bowl filled with the sample. Tests were performed at a rotating speed of $1200 \mathrm{rpm}$ and a temperature of $75{ }^{\circ} \mathrm{C}$ for $60 \mathrm{~min}$. After the completion of the test, the assembly of the oil cup and three balls was removed, the test oil was drained from it, the scar area was wiped with a tissue and then the three balls were clamped and kept under a microscope to measure the wear scar diameters. The surfaces of the four ball test specimens were examined using an FEI Quanta 200F SEM (FEI, Hillsboro, OR) equipped with EDX (scanning electron microscopy with energy-dispersive $\mathrm{X}$-ray spectroscopy). The parameters used were as follows: chamber pressure, $10 \mathrm{~Pa}$; high voltage, $20.00 \mathrm{kV}$; tilt, 0.00; takeoff, 35.00; amplitude time (AMPT), 102.4; resolution, 133.44.

\section{Results and discussion}

\section{Characterization of the $\mathrm{PzP}(-\mathrm{NHP})_{6}$ additive}

Although the formation of a waxy organo-inorganic hybrid salt with a dark orange color (Fig. 1a) from the white-colored

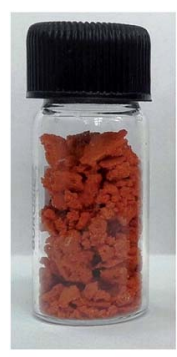

(a)

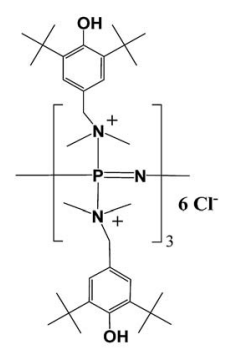

(b)
Fig. 1 (a) Physical form and (b) proposed molecular structure of the synthesized organo-inorganic hybrid salt $P z P(-N H P)_{6}$.

crystalline hexachlorocyclotriphosphazene and 2,6-di-tert-butyl-4(dimethylaminomethyl)phenol reactants gave direct evidence of the successful synthesis of $\boldsymbol{P z P}(-\mathbf{N H P})_{6}$, in order to find more evidence in favour of the successful synthesis of the novel organo-inorganic hybrid salt $\boldsymbol{P z} \boldsymbol{P}(-\mathbf{N H P})_{6}$ with the proposed molecular structure shown in Fig. $1 \mathrm{~b}$, various characterization techniques were used. The first direct evidence was provided by $\mathrm{CHN}$ analysis. The results observed in the elemental analysis were C, 64.83, H, 9.20 and N, 5.98. These values were in good agreement with the calculated values, which were $\mathrm{C}, 63.54, \mathrm{H}$, 9.10 and $\mathrm{N}, 6.54$. The increase in the $\mathrm{N}$ content clearly indicated the incorporation of the phenolic moieties into the phosphazene nucleus. The melting point of $\boldsymbol{P z} \boldsymbol{P}(-\mathbf{N H P})_{6}$ was also found to have increased to $200{ }^{\circ} \mathrm{C}$, whereas the $\mathrm{mp}$ of hexachlorocyclotriphosphazene was $114^{\circ} \mathrm{C}$.

The UV-visible spectra of hexachlorocyclotriphosphazene and the synthesized $\boldsymbol{P z} \boldsymbol{P}(-\mathbf{N H P})_{\boldsymbol{6}}$ in ethanolic water were recorded. The spectrum of hexachlorocyclotriphosphazene (Fig. 2) displayed the characteristic $\pi-\pi^{*}$ transition of phosphazene at around $200 \mathrm{~nm}$. The coupling of 2,6-di-tert-butyl-4-(dimethylaminomethyl)phenol to the phosphazene nucleus was confirmed by the slight hyperchromic/bathochromic shift in this $\pi-\pi^{*}$ transition to $204 \mathrm{~nm}$, and it became slightly more intense. In addition, the spectrum of $\boldsymbol{P z P}(-\mathbf{N H P})_{6}$ displayed three bands with low extinction coefficients at $230 \mathrm{~nm}$ (shoulder peak), $273 \mathrm{~nm}$ and $418 \mathrm{~nm}$, which may easily be assigned to the

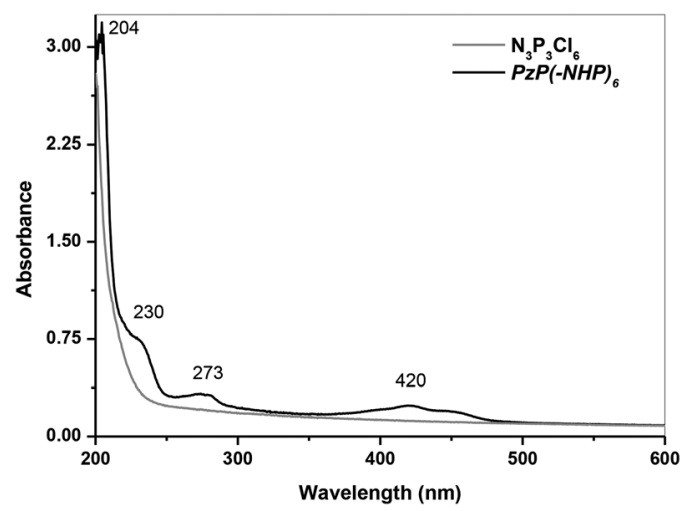

Fig. 2 UV-vis spectra of hexachlorocyclotriphosphazene $\left(\mathrm{N}_{3} \mathrm{P}_{3} \mathrm{Cl}_{6}\right)$ and the additive $P z P(-N H P)_{6}$. 
transitions of the substituent. The peaks at $230 \mathrm{~nm}$ and $273 \mathrm{~nm}$ are the characteristic primary and secondary absorption bands of the tert-butylated phenol ring (aromatic $\pi-\pi^{*}$ transition), whereas the absorption band at $420 \mathrm{~nm}$ may be attributed to intramolecular charge transfer within the reduced 2,6-di-tertbutyl-4-(dimethylaminomethyl)phenol moiety conjugated to the phosphazene nucleus (Fig. 2). ${ }^{22}$

FT-IR may also be an effective technique for demonstrating the coupling between phosphazene and 2,6-di-tert-butyl-4(dimethylaminomethyl)phenol. The FT-IR spectrum of phosphazene displayed a characteristic strong peak due to $\nu_{\mathrm{a}}$ (PNP) ring asymmetric stretching at $1212 \mathrm{~cm}^{-1}$, together with a peak due to $\nu_{\mathrm{s}}(\mathrm{PNP})$ ring asymmetric stretching at $875 \mathrm{~cm}^{-1}$. Both these bands formed a weak combination band at $2023 \mathrm{~cm}^{-1}$. Bands due to asymmetric and symmetric $\mathrm{P}-\mathrm{Cl}$ stretching also appeared at 601 and $523 \mathrm{~cm}^{-1}$, respectively (Fig. 3a). Fig. 3b shows the FT-IR spectrum of $\boldsymbol{P z} \boldsymbol{P}(-\mathrm{NHP})_{6}$, which reveals that all the characteristic peaks are present that correspond to the phosphazene nucleus and the hindered phenolic substituent, e.g. the band at $3641 \mathrm{~cm}^{-1}$ corresponds to the stretching of hindered phenolic $\mathrm{O}-\mathrm{H}$ bonds. Peaks due to asymmetric and symmetric $\mathrm{C}-\mathrm{H}$ stretching vibrations (owing to $\mathrm{CH}_{3}$ in the tertbutyl groups) were observed at 2957 and $2868 \mathrm{~cm}^{-1}$,
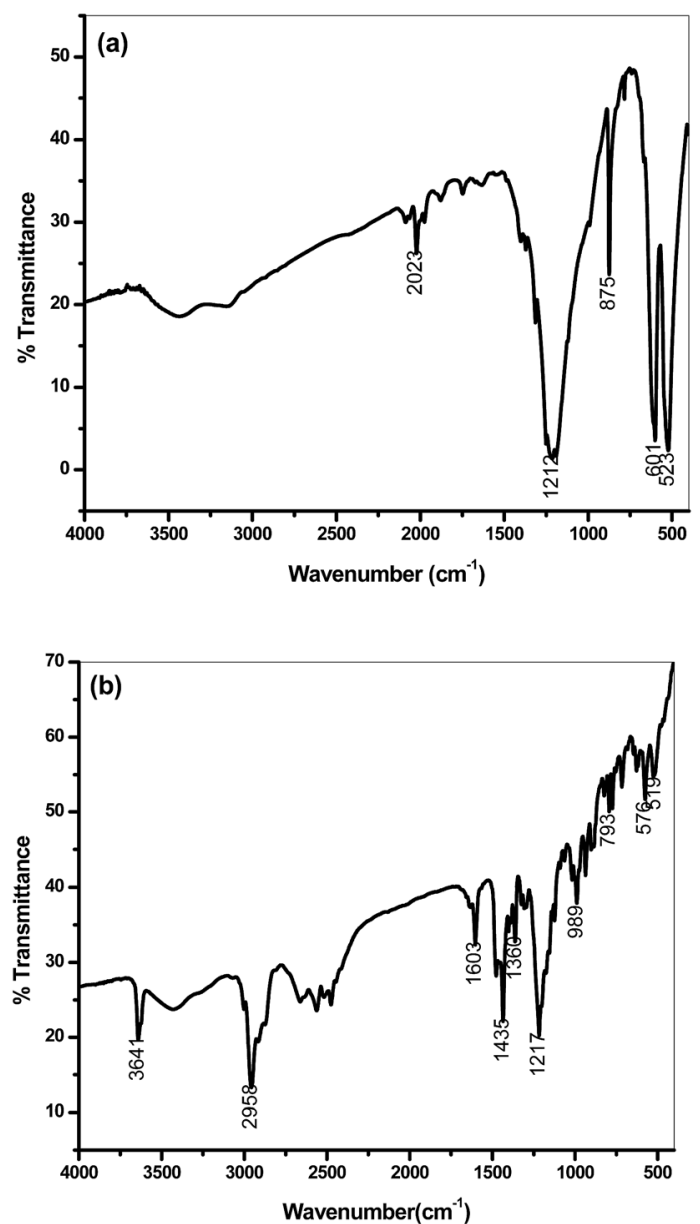

Fig. 3 FT-IR spectra of (a) hexachlorocyclotriphosphazene $\left(\mathrm{N}_{3} \mathrm{P}_{3} \mathrm{Cl}_{6}\right)$ and (b) the additive $P z P(-N H P)_{6}$. respectively. Another important peak at $1603 \mathrm{~cm}^{-1}$ may easily be assigned to aromatic $\mathrm{C}=\mathrm{C}$ stretching. The peaks at 1435 and $1360 \mathrm{~cm}^{-1}$ are attributed to $\mathrm{C}-\mathrm{H}$ bending $\left(\mathrm{CH}_{3}\right)$ and $\mathrm{O}-\mathrm{H}$ bending (in-plane), respectively. The presence of the phosphazene nucleus was strongly confirmed by the peak due to $\nu_{\mathrm{a}}$ (PNP) ring stretching at $1217 \mathrm{~cm}^{-1}$, which was slightly shifted towards higher wavenumbers in comparison to that of phosphazene. This can be explained in terms of an increase in positive charge around the phosphorus atom. The positively charged nitrogen atom in the substituent tries to attract the electron density around the phosphorus atom, which leads to an increase in the strength of the $\mathrm{P}=\mathrm{N}$ bond. The $\mathrm{m}$ band at $2500 \mathrm{~cm}^{-1}$ may be attributed to $>\mathrm{N}^{+}-\mathrm{H}$ stretching of protonated quaternary nitrogen atoms, which may occur owing to the available lone pair of the phosphazene nitrogen atoms.

In a similar way to the FT-IR spectra, the NMR spectra also presented strong evidence in favor of the structure of $\boldsymbol{P z} \boldsymbol{P}\left(-\mathrm{NH} \boldsymbol{P}_{\mathbf{6}}\right.$ given in Fig. 1. The ${ }^{13} \mathrm{C}$ NMR spectrum of the additive $\boldsymbol{P z P}(-\mathbf{N H P})_{6}$ is shown in Fig. 4. All the important signals of the incorporated 2,6-di-tert-butyl-4-(dimethylaminomethyl)phenol group were observed, as signals belonging to tert-butyl group carbons, $\mathrm{N}$-methyl carbons and benzylic $\mathrm{CH}_{2}$ carbons were observed between 30 and $64 \mathrm{ppm}$. Signals of aromatic ring carbons were observed between 115 and 160 ppm. Few other carbon signals were also seen, which corresponded to the minor impurity of unreacted 2,6-di-tert-butyl-4-(dimethylaminomethyl)phenol and the solvent. Similarly, the ${ }^{1} \mathrm{H}$ NMR spectrum of the additive $\boldsymbol{P z P}$ ($\boldsymbol{N H P})_{6}$ was found to display all the characteristic signals of all the protons corresponding to the hindered phenolic moieties and phenolic $\mathrm{OH}$ groups.

TG curves were recorded in order to estimate the working temperature range of the compound as an additive. By thermogravimetric (TG) analysis, it was revealed that the compound $\boldsymbol{P z} \boldsymbol{P}(-\mathrm{NHP})_{6}$ possessed high thermal stability in comparison to that of the reactant hexachlorocyclotriphosphazene $\left(\mathrm{N}_{3} \mathrm{P}_{3} \mathrm{Cl}_{6}\right)$, as their decomposition temperatures were found to be 110 and $165{ }^{\circ} \mathrm{C}$, respectively (Fig. 5). The addition of the 2,6-di-tert-butyl-4(dimethylaminomethyl)phenol moiety to cyclotriphosphazene provided it with thermal stability, because the decomposition temperature of 2,6-di-tert-butyl-4-(dimethylaminomethyl)phenol

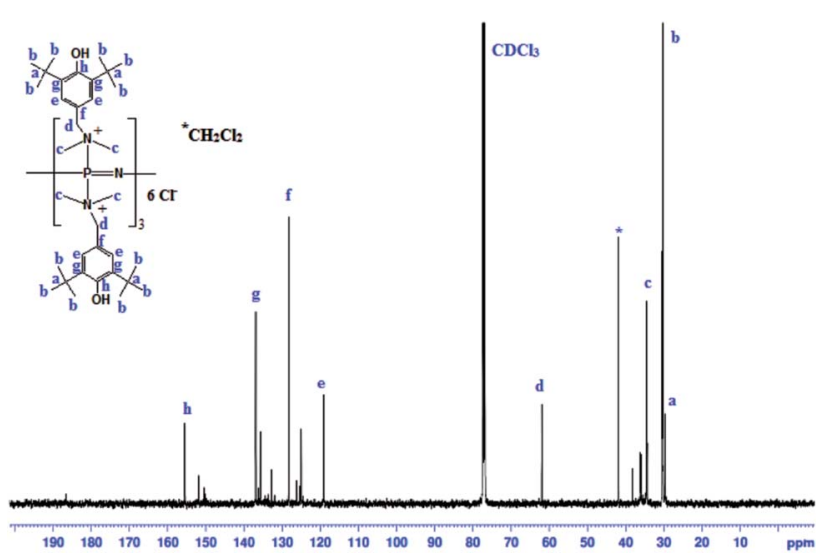

Fig. $4{ }^{13} \mathrm{C}$ NMR spectrum of the additive $P z P(-N H P)_{6}$ in $\mathrm{CDCl}_{3}$. 


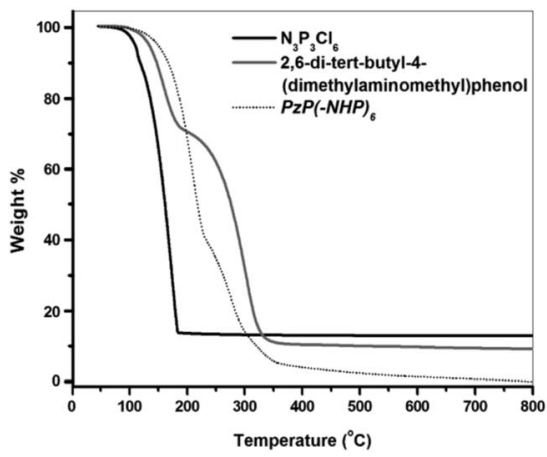

Fig. 5 TG curves of hexachlorocyclotriphosphazene $\left(\mathrm{N}_{3} \mathrm{P}_{3} \mathrm{Cl}_{6}\right), 2,6-$ di-tert-butyl-4-(dimethylaminomethyl)phenol, and $P z P(-N H P)_{6}$.

was also high at $150{ }^{\circ} \mathrm{C}$. One more reason may be the ionic nature of the final product.

After characterization, the solubility of the organo-inorganic hybrid salt $\boldsymbol{P z P}(-\mathbf{N H P})_{6}$ was measured in a polyol selected as a reference lube base oil. The compound was found to have very high solubility, as a clear solution formed when blending was carried out for only $5 \mathrm{~min}$ under sonication at $50^{\circ} \mathrm{C}$, as shown in Fig. 6.

Performance evaluation of $P z P(-N H P)_{6}$ as an antioxidant additive in polyol by the rotating bomb oxidation test (RBOT)

Because cyclic phosphazenes were reported to be inhibitors of the decomposition of perfluoropolyether lubricants, ${ }^{9}$ this gave indirect evidence in support of an inherent antioxidative stabilizing property of phosphazenes. The film-forming tendency of the phosphazene nucleus may also hinder metalto-lube contact and thus may retard the metal-catalyzed oxidation of the lube. Six hindered phenolic moieties were also incorporated further around the phosphazene framework via $\mathrm{P}-\mathrm{N}$ linkages in the $\boldsymbol{P z} \boldsymbol{P}(-\boldsymbol{N H P})_{6}$ structure. Hindered phenols are widely known as antioxidants for lubes and fuels. ${ }^{23} \mathbf{P z P}(-\mathbf{N H P})_{6}$ was therefore supposed to possess antioxidant activity. In order to confirm this, different blends were prepared with varying $\boldsymbol{P} z \boldsymbol{P}(-\mathbf{N H P})_{6}$ concentrations of 1000, 2000, 3000 and $4000 \mathrm{ppm}$ in a polyol base and rotating bomb oxidation tests (RBOT) were conducted according to ASTM D2272. ${ }^{17} \boldsymbol{P z P}(-\mathbf{N H P})_{6}$ was found to exhibit antioxidant properties with a concentration effect, as

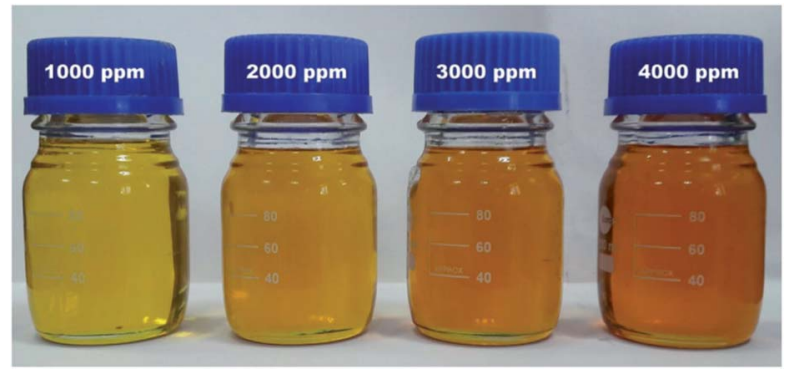

Fig. 6 Solubility of synthesized $P z P(-N H P)_{6}$ in polyol in different concentrations. was expected. For the blank polyol, the RBOT time was determined to be $6.72 \mathrm{~min}$. It increased to a value of $9.83 \mathrm{~min}$ at a concentration of $2000 \mathrm{mg} \mathrm{kg} \mathrm{kg}^{-1}$ and further increased to $10.35 \mathrm{~min}$ at the optimum concentration of $3000 \mathrm{ppm}$. No further increase in the RBOT time was observed with an increase in concentration beyond $2000 \mathrm{ppm}$, as at $4000 \mathrm{ppm}$ the RBOT time was determined to be $8.17 \mathrm{~min}$. The display of prooxidant behaviour at higher concentrations than the optimum is a well-known phenomenon of phenolic antioxidants. ${ }^{24,25}$ Therefore, $\boldsymbol{P} \boldsymbol{P} \boldsymbol{P}(-\boldsymbol{N H P})_{6}$ at a concentration of $3000 \mathrm{ppm}$ increased the oxidative stability of the polyol significantly by a factor of 1.54 (Fig. 7).

\section{Performance evaluation of $\mathrm{PzP}(-\mathrm{NHP})_{6}$ as an anticorrosion additive in polyol}

In a similar way to ZnDDP, the synthesized additive $\boldsymbol{P z P}(-\mathbf{N H P})_{6}$ contains heteroatoms such as $\mathrm{P}$ and $\mathrm{O}$ and therefore it may also have anticorrosion and antiwear properties, as ZnDDP is well known to have excellent anticorrosion and antiwear properties together with antioxidant characteristics. Blends of the additive $\boldsymbol{P} \boldsymbol{z} \boldsymbol{P}(-\boldsymbol{N H P})_{6}$ were therefore prepared in a polyol base oil with different concentrations by sonication at $50{ }^{\circ} \mathrm{C}$, and their anticorrosion activity was tested according to standard corrosion test procedures. ${ }^{18,19}$ The additive $\boldsymbol{P z} \boldsymbol{P}(-\boldsymbol{N H P})_{\boldsymbol{6}}$ was found to be a good anticorrosion additive. It can easily be observed that its anticorrosion activity increased with an increase in concentration, as shown in Table 1 . The best results were found at an optimum concentration of $4000 \mathrm{ppm}$, at which the values of the weight loss, corrosion rate and penetration rate decreased to $0.01 \mathrm{mg}, 0.01 \mathrm{mdd}$ and $0.001 \mathrm{mpy}$ from the original values of $0.40 \mathrm{mg}, 0.39 \mathrm{mdd}$ and $0.050 \mathrm{mpy}$ that were determined for the polyol lube base oil. The difference in acid value also decreased from a value of 22.33 for the polyol base oil to 10.74 for the PzP(NHP) $)_{6}$ sample with a concentration of 4000 ppm. A negative effect was observed on the anticorrosion property at concentrations higher than $4000 \mathrm{ppm}$, which may be due to an increase in acidity caused by the additive itself, which induced corrosion. As the reactant 2,6-di-tert-butyl-4-(dimethylaminomethyl)phenol

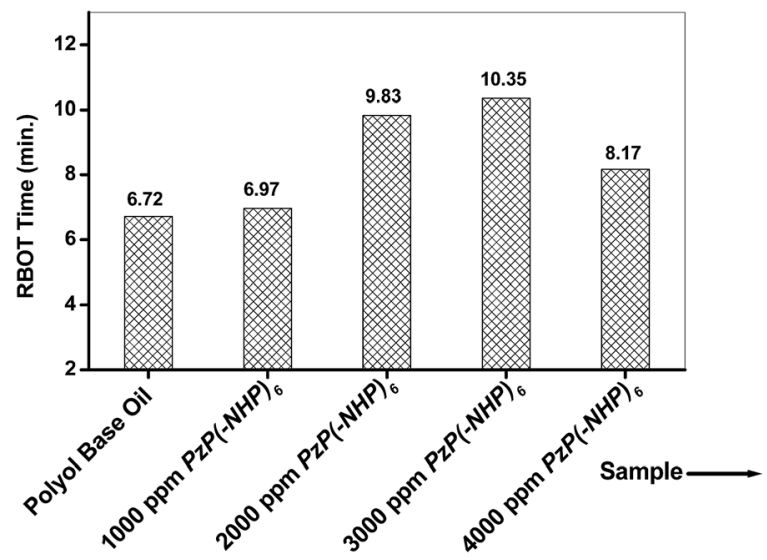

Fig. 7 RBOT time of blank polyol and its blends with the $P z P(-N H P)_{6}$ additive at varying concentrations. 
Table 1 Corrosion behavior of carbon steel in base oil and various blends containing the additive with respect to their acid values

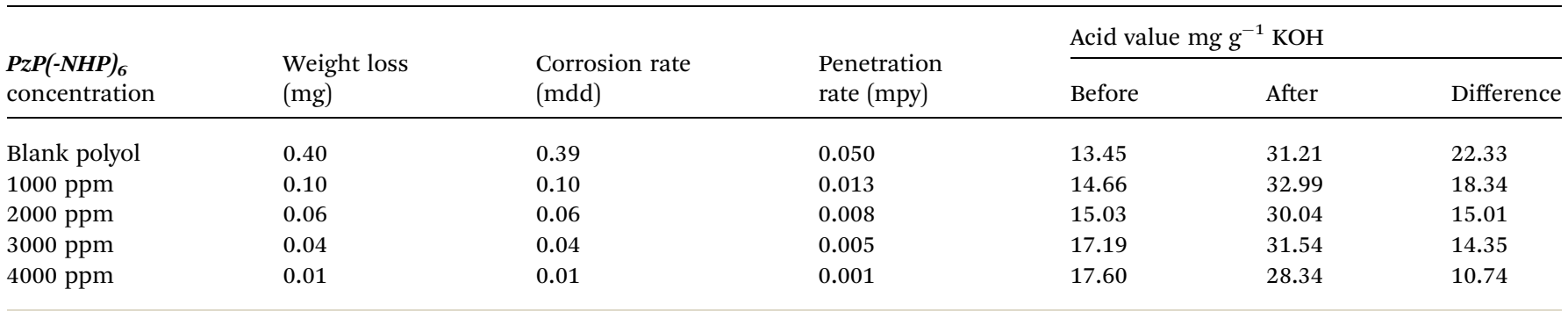

is itself a tertiary amine and thus may act as an anticorrosion agent, a corrosion test was also conducted by adding $4000 \mathrm{ppm}$ 2,6-di-tert-butyl-4-(dimethylaminomethyl)phenol to the polyol. The results obtained for the weight loss, corrosion rate and penetration rate were $0.02 \mathrm{mg}, 0.02 \mathrm{mdd}$ and $0.002 \mathrm{mpy}$, respectively. This revealed that the anticorrosion property was slightly inferior to that of the synthesized additive at a concentration of $4000 \mathrm{ppm}$. In fact, the phosphazene nucleus enabled the additive to form a layer over the metal surface and thus hindered the contact of the metal with the acidic oxidized moieties that were generated, even though it contained chlorine atoms. However, the difference in the TAN proved to be slightly low at 9.45, which may be attributed to the high acidneutralizing capability of the amines.

In order to provide visual evidence of the anticorrosion activity of $\boldsymbol{P} z \boldsymbol{P}(-\mathbf{N H P})_{6}$, high-resolution SEM images of the metal specimens immersed in the polyol base oil and the $4000 \mathrm{ppm}$ $\boldsymbol{P z P}(-\mathrm{NHP})_{6}$ sample were also recorded, as shown in Fig. 8, which clearly indicates the inhibition of the formation of corroded pits on the surface of the metal specimen when 4000 ppm $\boldsymbol{P} z \boldsymbol{P}(-\mathrm{NH} \boldsymbol{P})_{6}$ was used.

\section{Performance evaluation of $P z P(-N H P)_{6}$ as lubricity additive}

Owing to the presence of the polar phosphazene nucleus in the structure of $\boldsymbol{P z P}(-\mathrm{NHP})_{6}$, which contains a ring of nitrogen and phosphorus atoms, it may have an affinity for a metal surface to form a surface film, which hinders contact with the metal, and may provide friction-reducing and antiwear properties in a similar way to ZnDDP. For the same reason, phosphazene derivatives have also been investigated in the past with respect to their antiwear and antifriction characteristics, in particular

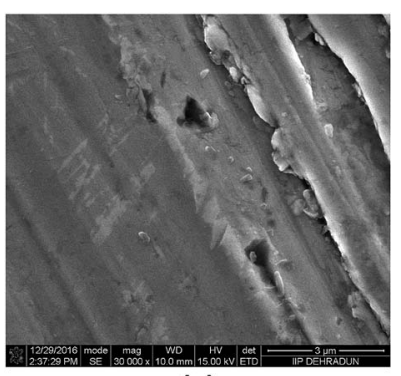

(a)

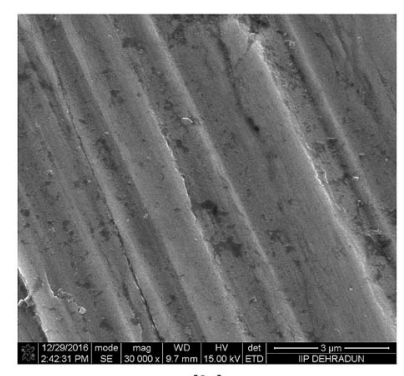

(b)
Fig. 8 SEM images of corroded steel specimens with (a) blank polyol

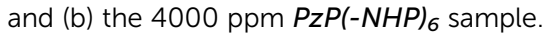

for steel-steel contact. ${ }^{8,10}$ In view of this, the antiwear and antifriction properties of $\boldsymbol{P} z \boldsymbol{P}(-\mathbf{N H P})_{6}$ in terms of the AWSD and average friction coefficient, respectively, were also determined by four-ball tests performed on polyol samples blended with $\boldsymbol{P z P}(-\mathrm{NHP})_{6}$ in accordance with ASTM D4172B. ${ }^{21}$ Fig. 9a and b show plots of the average wear scar diameter and average friction coefficient as a function of the concentration of the additive. It is observed from the plots that the concentration of the additive had a considerable effect on the lubricity properties. With an increase in the concentration of the additive in the blend, decreases in the values of the AWSD and average friction coefficient were clearly observed up to the optimum concentration of $3000 \mathrm{ppm}$, at which $\boldsymbol{P z P}(-\mathbf{N H P})_{6}$ displayed the best antiwear and antifriction performance. An increase in the concentration of the additive beyond the optimum value had a negative effect on the tribological properties. At a concentration of $3000 \mathrm{ppm}$, the AWSD was reduced by $15.81 \%$ to $585.83 \pm$ $11.72 \mu \mathrm{m}$ in comparison to the AWSD when the reference polyol base alone was used for lubrication, the value of which was $695.83 \pm 16.86 \mu \mathrm{m}$. At a concentration of $3000 \mathrm{ppm}$, the average friction coefficient was reduced by $27.27 \%$ to $0.080 \pm 0.0097$ in comparison with that for the reference polyol base alone, the
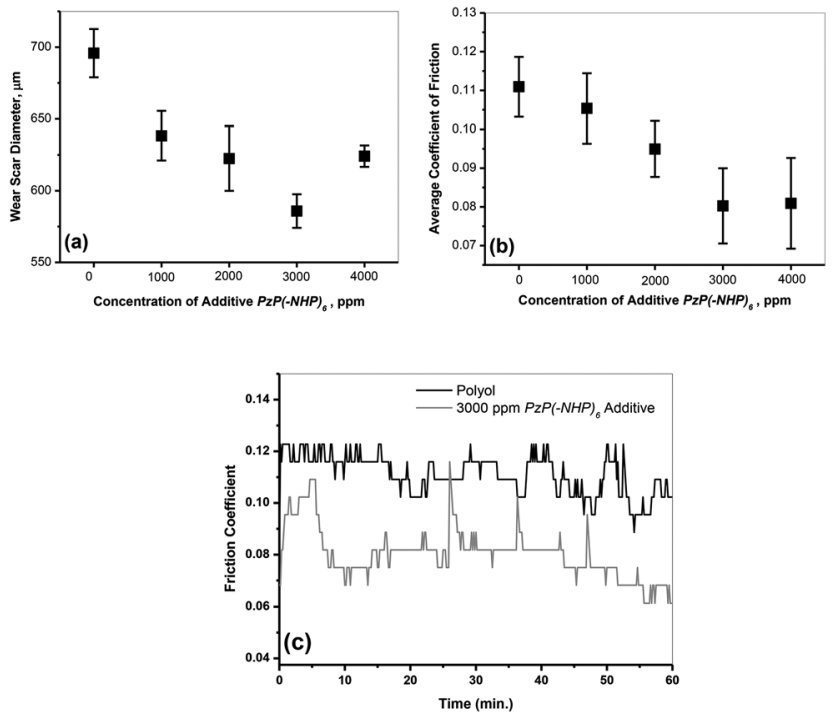

Fig. 9 Reduction in (a) AWSD and (b) average friction coefficient with an increase in the concentration of $P z P(-N H P)_{6}$ in the polyol base; (c) graph of friction coefficient $v s$. time for the polyol alone and a blend

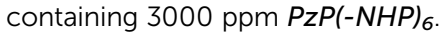


value of which was $0.110 \pm 0.0077$. Evidence of the formation of a stable film was obtained from the graph of friction coefficient versus time in the cases of the polyol alone and a blend of 3000 ppm $\boldsymbol{P z P}(-\mathbf{N H P})_{6}$ in the polyol. In the case of the lubrication system containing the synthesized additive, after an initial increase as the time of contact increased the friction coefficient also decreased (Fig. 9c).

In order to establish the mechanism of the tribological activity, the morphology of the worn surface of the specimen ball was investigated by performing SEM-EDX analysis (scanning electron microscopy with energy-dispersive X-ray spectroscopy). Fig. 10a and b show SEM micrographs of the worn test specimens lubricated with the sample containing $3000 \mathrm{ppm}$ $\boldsymbol{P z} \boldsymbol{P}(-\mathbf{N H P})_{6}$ in the polyol. Few shallow contour fluctuations and furrows due to wear can be seen. No sign of corroded pits was observed in the specimens, apart from some wear debris. The worn surface lubricated by the additive is largely smooth, which indicates that the synthesized additive $\boldsymbol{P z} \boldsymbol{P}(-\boldsymbol{N H P})_{6}$ had a boundary lubrication effect and hindered the direct contact of the frictional pairs. The EDX analysis and elemental mapping show that carbon, iron, chromium, and oxygen are prominent on the surface owing to the composition of the steel surface, together with the presence of phosphorus and nitrogen

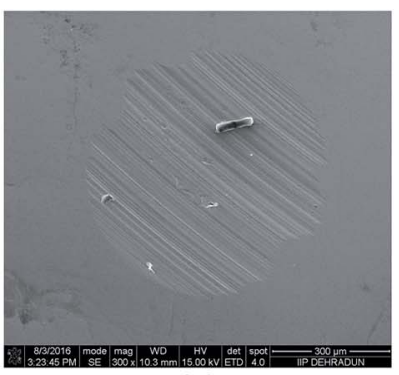

(a)

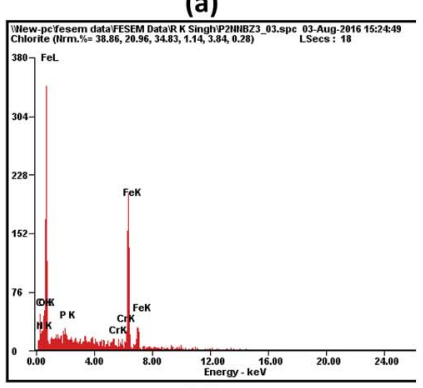

(c)

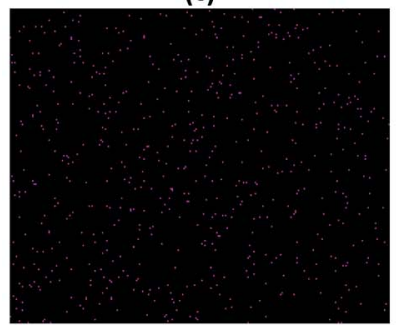

(e)

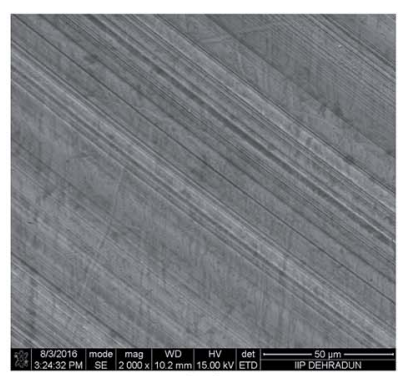

(b)

\begin{tabular}{|c|c|c|}
\hline Element & $\mathbf{W t} \%$ & At \% \\
\hline $\boldsymbol{C} \boldsymbol{K}$ & 21.38 & 43.70 \\
\hline $\boldsymbol{N} \boldsymbol{K}$ & 08.47 & 14.84 \\
\hline $\boldsymbol{O} \boldsymbol{K}$ & 09.48 & 14.55 \\
\hline $\boldsymbol{P} \boldsymbol{K}$ & 00.53 & 00.42 \\
\hline $\boldsymbol{C} \boldsymbol{K}$ & 01.30 & 00.61 \\
\hline $\boldsymbol{F e K}$ & 58.84 & 25.87 \\
\hline
\end{tabular}

(d)

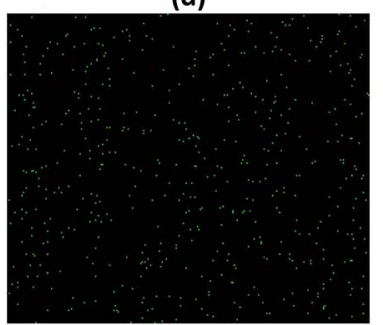

(f)
Fig. 10 (a) and (b) SEM micrographs of the worn test specimen balls lubricated with a blend of $3000 \mathrm{ppm} P z P(-N H P)_{6}$ in the polyol; (c) and (d) results of EDX analysis; (e) and (f) elemental mapping with respect to $\mathrm{P}$ and $\mathrm{N}$.
(Fig. 10c-f). This is strong evidence in favour of the contribution of the additive to the formation of a film on the surface.

\section{Conclusions}

A novel organo-inorganic hybrid salt, namely, $\boldsymbol{P z P}(-\mathbf{N H P})_{6}$, was synthesized by the reaction between hexachlorocyclotriphosphazene $\left[\mathrm{N}_{3} \mathrm{P}_{3} \mathrm{Cl}_{6}\right]$ and 2,6-di-tert-butyl-4-(dimethylaminomethyl)phenol in dichloromethane. The molecule includes the important phosphazene ring, which contains polar nitrogen and phosphorus elements, surrounded by hindered phenolic substituents with tert-butyl groups. It may therefore display an affinity for a metal surface to form a surface film, which leads to anticorrosion, antiwear, and antifriction properties together with antioxidant characteristics. Metal-catalyzed oxidative degradation can also be suppressed by this protective film. After characterization of the synthesized molecule by CHN, UV-vis, FT-IR, NMR and TG, performance evaluation with regard to the abovementioned properties was conducted using standard methods. The $\boldsymbol{P z P}(-\mathbf{N H P})_{6}$ additive was found to exhibit excellent antioxidant property, whereas its performance was found to be moderate with respect to anticorrosion, antiwear and antifriction properties. A concentration of $3000 \mathrm{ppm} \boldsymbol{P z} \boldsymbol{P}(-\mathbf{N H P})_{6}$ decreased the AWSD and average friction coefficient by $15.81 \%$ and $\sim 27.27 \%$, respectively, in comparison to those for the blank polyol.

\section{Acknowledgements}

We kindly acknowledge the Director, IIP for his kind permission to publish these results. The Analytical Division of the Institute is kindly acknowledged for providing analysis of samples.

\section{References}

1 R. Luther and T. Mang, Lubricants, 10. Disposal, Recycling, and Safety Aspects, in Ullmann's Encyclopedia of Industrial Chemistry, Wiley-VCH Verlag GmbH \& Co. KGaA, 2011.

2 C. I. Betton, Lubricants and their environmental impact, in Chemistry and technology of lubricants, ed. M. Roy, R. M. Mortier, M. F. Fox and S. T. Orszulik, Springer, Heidelberg, 2010, p. 435.

3 Report No. EPA800-R-11-002, Environmentally acceptable lubricants, United States Environmental Protection Agency, Office of Wastewater Management, Washington DC, 2011.

4 P. Nagendramma and S. Kaul, Renewable Sustainable Energy Rev., 2012, 16, 764-774.

5 R. K. Hewstone, Sci. Total Environ., 1994, 156(3), 243-254.

6 M. A. Nicholls, T. Do, P. R. Norton, M. Kasrai and G. M. Bancroft, Tribol. Int., 2005, 38(1), 15-39.

7 B. A. Omotowa, B. S. Phillips, J. S. Zabinski and J. M. Shreeve, Inorg. Chem., 2004, 43(17), 5466-5471.

8 J. Zhu, Y. Liang and W. Liu, Tribol. Int., 2004, 37, 333-337.

9 D. J. Perettie, Tribol. Int., 2003, 36, 489-491.

10 J. Zhu, W. Liu, R. Chu and X. Meng, Tribol. Int., 2007, 40, 1014.

11 X. Wang, A. Y. X. Tan, C. M. Cho, Q. Ye, C. He, R. Ji, H. Q. Xie, J. W. H. Tsai and J. Xu, Lubr. Sci., 2017, 29, 31-42. 
12 R. K. Singh, A. Kukrety, A. K. Chatterjee, G. D. Thakre, G. M. Bahuguna, S. Saran, D. K. Adhikari and N. Atray, Ind. Eng. Chem. Res., 2014, 53(48), 18370-18379.

13 R. K. Singh, S. Pandey, R. C. Saxena, G. D. Thakre, N. Atray and S. S. Ray, J. Ind. Eng. Chem., 2015, 26, 149-156.

14 R. K. Singh, S. Pandey, R. C. Saxena, G. D. Thakre, N. Atray and S. S. Ray, New J. Chem., 2015, 39, 5354-5359.

15 P. P. Latha, R. K. Singh, A. Kukrety, M. Bhatt, R. C. Saxena and S. L. Jain, ACS Sustainable Chem. Eng., 2016, 4(3), 9991005.

16 D. E. Goins and H. M. Li, US Pat. No. 5,105,001, 1992.

17 ASTM D2272-11, Standard test method for oxidation stability of steam turbine oils by rotating pressure vessel, in Annual Book of ASTM Standards, ASTM International, West Conshohocken, PA, 2011.

18 Corrosion Testing Procedure, ed. F. A. Champion, Champion \& Hall, 1964, p. 66.
19 Handbook of Corrosion Testing and Evaluation, ed. W. H. Ailor, John Wiley \& Sci, Inc., 1971, p. 119.

20 ASTM D664-11a, Standard test method for acid number products by potentiometric titration, in Annual Book of ASTM Standards, ASTM International, West Conshohocken, PA, 2011.

21 ASTM D4172B, Standard test method for wear preventive characteristics of lubricating fluid (Four-Ball Method), in Annual Book of ASTM Standards, ASTM International, West Conshohocken, PA, 2010.

22 M. B. Sayed, Spectrosc. Lett., 2002, 35(6), 799-809.

23 L. R. Rudnick, Lubricant additives: chemistry and applications, Taylor \& Francis Group, Boca Raton, 2009.

24 B. Kowalski, Thermochim. Acta, 1993, 213, 135-146.

25 B. Kowalski, Thermochim. Acta, 1991, 184, 49-57. 